\title{
ВТОРИЧНЫЕ ГЕОХИМИЧЕСКИЕ ПРОЦЕССЫ В КАЧЕСТВЕ АТРИБУТА НЕФТЕГАЗОНАСЫЩЕННОСТИ ПЕСЧАНЫХ КОЛЛЕКТОРОВ ТАМБЕЙСКОГО МЕСТОРОЖДЕНИЯ
}

\author{
Мельник Игорь Анатольевич1, \\ melnik@tpu.ru
}

\section{Родивилов Данила Борисович2,} rodivilovdb@gmail.com

\author{
Никитин Иван Александрович ${ }^{3}$, \\ nikitin_ivan_alex@mail.ru \\ 1 Национальн ый исследовательский Томский политехнический университет, \\ Россия, 634050, г. Томск, пр. Ленин а, 30. \\ 2 Филиал Газпром недра НТЦ ООО «Газпром недра», \\ Россия, 625000, г. Тюмен ь, ул. Герцен а, 70. \\ 3 НИПИ «СургутНИПИнефть», \\ Россия, 628415, г. Сургут, ул. Энтузиастов, 48.
}

\begin{abstract}
Актуальность исследования определяется рассмотренной возможностью при отсутствии керна выявлять пропущенные продуктивные залежи в песчаных интервалах по материалам как старого, так и нового фонда геофизических исследований скважин. Современные требования к созданию и разработке на высочайшем уровне минерально-сырьевой базы РФ предпологают введение большого количества принципиально новых месторождений и залежей, рентабельность которых устанавливается уровнем изученности. Во многих случаях просто необходимо снизить врменные рамки и капитальные затраты на геологоразведочные работы в силу применения и доисследования данных в прошлом изученных месторождений. Район Тамбейского месторождения является достаточно перспективным в свете активного освоения нефтегазовых площадей Ямала. Цель: иллюстрация использования таких параметров, как статистические интенсивности вторичных пелитизации и карбонатизации, в качестве индикаторов нефртегазонасыщенности песчаных коллекторов на различных участках Тамбейского месторождения.

Объекты: меловые песчаные отложения нефртегазоносного месторождения Тамбейской площади полуострова Ямал.

Результаты. Показаны петрологически-геохимические индикаторы нефтегазоносности и их определение по материалам ГИС. Проиллюстрированы сопоставления результатов статистической интерпретации материалов ГИС с результатами петрограффического исследования керна. В работе использована инновационная технология статистической интерпретации материалов ГИС на предмет выявления интенсивностей вторичных геохимических процессов при индикации нефттегазоносных коллекторов. Подтверждено, что на Северо-Тамбейском участке с 80 \% вероятностью индикатором газонасыщенности пласта является интенсивность вторичной карбонатизации при условии превышения её критической величины 0,22 усл. ед., а на Западно-Тамбейском участке индикатором нефртегазонасыщенности коллекторов является интенсивность вторичной пелитизации при условии превышения их величин до 0,084 усл. ед.
\end{abstract}

\section{Ключевые слова:}

Наложено-эпигенетический процесс, вторичная пелитизация, вторичная карбонатизация, низкоомный коллектор, углеводороды, геохимический индикатор нефтегазоносности, геофизические исследования скважин.

\section{Введение}

Образования аутигенных минералов в горных породах при вторичных геохимических процессах в большинстве своем обусловлены наложенным эпигенезом, проходящим в результате субвертикальной миграции флюидов по проницаемым зонам литосферы, вследствие действия градиента литостатического давления. В зависимости от химического состава флюида и степени различия $\mathrm{pH}$ между внешним флюидом и заполняемой им средой происходят геохимические преобразования породообразующих минералов с различной интенсивностью. Вновь сформированные минералы будут являться индикаторами качества и свойств мигрирующих флюидов. По интенсивностям вторичных геохимических процессов можно судить о характере насыщения пласта и выделять интересующие нас углеводородные интервалы [1-5].
Интенсивность процессов можно определить по количеству аутигенных минералов, образованных в результате вторичных преобразований (и генетически с ними связанных) аллотигенных минералов относительно их первоначального содержания на единице площади. Для этого необходимо провести минералого-петрографическое исследование образцов керна. Концентрацию первичных аллотигенных минералов часто выявляют по косвенным признакам. При отсутствии керна качество и степень вторичных геохимических изменений среды можно определить по результатам статистическо-корреляционной интерпретации материалов геофизических исследований скважин (ГИС) [6, 7].

Многочисленные исследования дали нам понять, что показателем присутствия углеводородов в исследуемых песчаных пластах являются вычисляемые 
статистическо-корреляционные параметры (СКП) интенсивностей различных эпигенетических процессов в пределах их определенных граничных величин $[7,8]$. Сопоставив результаты испытаний пластов с выборочными величинами СКП интенсивностей различных процессов, выбираем среди них геохимический индикатор и его граничные величины для нефтегазонасыщенных пластов. В итоге, определив критерий поиска углеводородных (УВ) интервалов для исследуемой площади, мы можем выявить пропущенные низкоомные залежи, обусловленные вторичными процессами [9].

Целью данной статьи является иллюстрация результатов инновационных исследований по технологии определения СКП (на основе данных ГИС) интенсивностей вторичных процессов, обусловленных УВ насыщением в меловых песчаных отложениях Тамбейского нефтегазоносного месторождения полуострова Ямал. Показаны геохимические индикаторы нефтегазоносности и результаты сопоставления данных статистической интерпретации материалов ГИС с петрографическими изучением шлифов керна.

\section{Краткое теоретическое обоснование}

До поступления внешних флюидов в песчаный коллектор порода песчаника находится в равновесном состоянии с точки зрения прохождения химических процессов. После поступления флюидов с различной $\mathrm{pH}$ относительно заполняемой среды равновесие нарушается, и проходимая химическая реакция влияет как на трансформацию минералов, так и на петрофизические свойства породы коллектора. Например, в результате поступления кислых глубинных флюидов с растворенной углекислотой $(\mathrm{pH}=4,0-5,0)$ углекислотный метасоматоз протекает следующим образом полевые шпаты либо глиноземы, вступая в химическое взаимодействие с растворенным в воде углекислым газом, преобразуются в каолиниты с образованием катионов железа, калия, а также угольной и кремневой кислот $[5,10]$.

Фиксируется растворение как заполняющего поры цемента, так и матричного алюмосиликата вследствие высоких показателей кислотности. Наблюдается увеличение проницаемости, а также емкости коллектора [1]. Образующиеся катионы мигрируют к отрицательно заряженной глинистой поверхности двойного электрического слоя (ДЭС), тем самым повышая диффузионную плотность зарядов и соответствующую поверхностную электропроводность гетерогенной породы $[6,11]$. Данную дополнительную компоненту электропроводности невозможно учесть при стандартной интерпретации материалов ГИС, что может привести к ошибочной интерпретации характера насыщения коллектора и соответствующему пропуску продуктивного пласта [12].

При поступлении в полиминеральный, с содержанием полевых шпатов, песчаный коллектор в породе синхронно увеличиваются содержания глинистых минералов (каолинитов) относительно кислых внешних флюидов и её пористость. Очевидно, это априори предполагает образование положительной регрессии в корреляциионой связи независимых петрофизических параметров выборок глинистости с пористостью. При отсутствии вторичных геохимических процессов, как правило, между ними регрессия отрицательная и открытая пористость частично зависит от глинистости. Поэтому образование положительной регрессии между рассматриваемыми петрофизическими параметрами по данным ГИС в исследуемом песчаном интервале выявляет наличие процесса вторичной каолинитизации.

Вторичные карбонаты могут образоваться после разгерметизации флюидоупора с резким понижением давления, и в зависимости от времени прохождения метасоматоза в нижних слоях породы с соответствующей остаточной кислотностью среды происходит «вскипание» углекислоты и ощелоченный мигрирующий в верхние отложения раствор карбонатизирует (кальцитизирует) породу [13].

При образовании коллектора на завершающих стадиях в области водонефтяного контакта (ВНК) повышается рН среда, связанная с соединением щелочного раствора с водным, который был вытеснен вниз углеовдородами [12]. Перешедшие в раствор ионы редких земель могут изоморфно входить в структуру образующихся карбонатов, повышая тем самым макроскопическое сечение поглощения тепловых нейтронов (МСП). В таком случае вторичные карбонаты выявляются в случае положительной регрессии карбонатов с МСП породы при увеличении карбонатизации песчаника.

В естественных условиях пирит формируется в основном за счет химического взаимодействия сероводорода и железистых соединений, растворенных в воде. Соединения с серой всегда присутствуют в углеводородной смеси, поэтому пирит часто ассоциируется с УВ [14]. В полимиктовой песчаной породе мезозойских отложений Западной Сибири пирит является наиболее часто встречающимся железосодержащим минералом с электропроводящими свойствами. Поэтому отрищательная регрессия содержания железа с УЭС породы с большой вероятностью будет ассоичироваться с пиритами.

Вторичные изменения железосодержащего биотита, такие как хлоритизация, гидратация с сидеритизацией, также повышают электропроводность породы, и в этом случае отрицательная регрессия железа с УЭС породы обусловлена процессами преобразования аллотигенного биотита [13].

Пелитизаиия калиевых полевых шпатов с последующим образованием гидратированной пленки глинистых минералов (например, крустификационного хлорита) приводит замыкающую поверхностную электрическую цепь к формированию обратной корреляционной связи УЭС с содержанием калия.

Образование вторичных пиритов, пелитов в случае формирования поверхностной электрической цепи, как и образование двойного электрического слоя глин с повышенной электрической проводимостью вследствие дифузии свободных катионов приводят к формированию в пластах низкоомных коллекторов с возможным УВ насыщением. 
Итак, перечисленные регрессии между выборочными материалами ГИС, петрофизическими и петрохимическими данными позволяют (на качественном уровне) выделять песчаные интервалы с вторичными геохимическими процессами. Но нам нужны и количественные характеристики - интенсивности этих процессов.

Статистическо-корреляционные параметры $i$ интенсивности различных эпигенетических процессов можно определять на основании корреляций между двумя дискретными массивами данных, обоснованными физико-химической связью [6-8]. Главным результатом связи двух отдельных выборок $(X, Z)$ являются коэффициенты корреляции $R$ и аппроксимации $R^{2}$, определяющиеся следующим образом:

$$
R=\frac{\sum_{i=1}^{n}\left(x_{i}-\bar{x}\right)\left(z_{i}-\bar{z}\right)}{n \sigma_{x} \sigma_{z}},
$$

где $\sigma$ - стандартное отклонение выборочных значений. Коэффициент аппроксимации отражает долю дискретных значений от общего их количества $n$, соответствующую определенному тренду (например, $f=Z(X))$, т. е. качество, «тесноту» их связи.

Для определения доли интервала пласта, в которой вторичный процесс преобразует вещество, количественный статистический параметр вычисляется по следующей зависимости:

$$
Y=\frac{q}{n}=\frac{\sum_{i=1}^{n} q_{i}}{n},
$$

где $q$ - количество выборочных значений при условии исследуемой регрессии $R_{i}>| \pm 0,6| ; n$ - генеральная выборка (количество исследуемых дискретных значений пласта). Статистический параметр $Y$ выражает интервальную меру влияния вторичного процесса в песчаниках исследуемых пластов, т. е. показывает количественную долю преобразованного вещества исследуемого интервала. Назовем его интервальный параметр.

Различные теоретические и эмпирические исследования показали, что статистическая интенсивность вторичных процессов (каолинитизация, пелитизация, пиритизация и карбонатизация) исследуемого интервала песчаного пласта по скважине равна произведению вычисляемых СКП [6]:

$$
i=R^{2} Y \text {. }
$$

Покажем результативность применения рассмотренной технологии на примере сопоставления эмпирических данных исследований песчаных пластов мезозоя Тамбейского месторождения полуострова Ямал с вычисляемыми статистическими интенсивностями вторичных процессов.

\section{Краткое описание методики определения выборочных значений}

К исследуемым выборочным значениям относятся кажущееся УЭС породы, коэффициенты глинистости $\left(k_{\text {гл }}\right)$, общей пористости $\left(k_{\text {п }}\right)$, плотности, карбонатности $\left(k_{\text {кар }}\right)$, макроскопическое сечение поглощения тепловых нейтронов (МСП) и относительное содержание железа.

Все исследуемые выборочные данные определяются для каждого песчаного интервала отдельно после калибровки. В начале в разрезе скважины выбирается песчаный интервал, где имеются данные ГИС: нейтронный каротаж по тепловым нейтронам (ННКт) либо нейтронный гамма каротаж (НГК), данные кажущего УЭС (например, двухметровый градиент-зонд ГЗ-3), гамма-каротажа скважин (ГК) и собственной поляризации (ПС). По зависимостям $k_{\text {гл }}=\mathrm{F}(\Gamma К, \Pi \mathrm{C}), k_{\Pi}=\mathrm{F}(\mathrm{HК})$ и $k_{\text {кар }}=\mathrm{F}(\mathrm{HК}, \Gamma К, ~ П С)$ после калибровки, по которой для каждой зависимости определяются калибровочные коэффициенты пропорциональности и на основании зависимостей поточечно (по глубине песчаного интервала) вычисляются коэффициенты глинистости, пористости и карбонатности. Например, предварительно в разрезе скважины по данным каротажа определяются величины $\Pi_{(\max )}$ при $k_{\text {гл }}=100 \%$ и ПС(min) при $k_{\text {гл }}=0 \%$, далее усредненое (по интервалу) отношение разниц приравнивают к вычисленной средней глинистости интервала и по отношению средней глинистости и среднего отношения определяется калибровочный коэффициент. Так для всех зависимостей.

При определении относительного содержания железа и МСП калибровочные коэффициенты вычисляются на основании уже известных алгоритмов [6]. На базе ранее проведенных лабораторных исследований керна нескольких тысяч песчаных интервалов в меловых и юрских пластах по Западно-Сибирской нефтегазовой провинции в полимиктовой песчаной породе были определены средние содержания породообразующих и редкоземельных химических элементов, оказывающих наибольшее влияние на показания нейтронного каротажа. По значениям средних содержаний химических элементов и данным нейтронного каротажа, а также пористости, глинистости и карбонатности, на основании уже выявленных зависимостей вычисляются калибровочные коэффициенты по каждому интервалу отдельно.

После определения калибровочных коэффициентов на базе системы уравнений [6] вычисляются относительные содержания бора и железа, в наибольшей степени влияющих (после водорода) на показания нейтронного каротажа и химически активных элементов. Остальные элементы связаны зависимостями с глинистостью и карбонатностью песчаного интервала. В полимиктовой песчаной породе содержание калия оказалось связано функциональной зависимостью с содержанием бора и показанием ГК.

\section{Анализ и обобщение результатов исследования}

В данной работе исследуются два участка Тамбейского месторождения: северный и западный. Проведенный статистический анализ результатов инновационной интерпретации материалов ГИС позволил выявить петрологические индикаторы присутствия УВ в песчаных интервалах как на западном, так и на северном участках Тамбейского месторождения. Покажем итоги выявления индикаторов в песчаных по- 
родах, а также результаты сопоставления вычисленной интенсивности вторичных процессов с описанием шлифов образцов керна и результатами определения общего состава карбонатных минералов методом полуколичественного рентгеноструктурного анализа.

Проведенные исследования песчаных пластов мелового комплекса отложений Тамбейских участков обнаружили, что для каждого нефтегазоносного участка определяются свои, индивидуальные индикаторы нефтегазонасыщенности пласта. Сопоставления полученных результатов статистической интерпретации песчаных интервалов с результатами испытаний пластов позволяют сформировать две выборки вычисленных статистических параметров для их дальнейшего анализа. При сопоставлении двух выборок и их значительном количественном различии количество значений данных выборок уравнивалось.

Для Западно-Тамбейского участка массив данных (для четырех параметров интенсивностей) УВ насыщенных интервалов составил 47 выборочных значений и 32 значения для водонасыщенных пластов. По результатам статистического анализа определился параметр-индикатор нефтегазонасыщенности пластов. Это интенсивность пелитизации, средняя величина которой в УВ насыщенной породе на $47 \%$ меньше средней величины водонасыщенного пласта, что является наибольшей отличительной особенностью в сравнение с остальными статистическими параметрами. Если из выборки убрать нулевые значения, то средняя величина интенсивности УВ насыщенного коллектора будет отличаться на $33 \%$ от средней интенсивности в водоносном пласте. Кроме того, парный двухвыборочный $t$-тест для средних показал значимое отличие выборок интенсивностей пелитизации газонасыщенных и водонасыщенных пластов с коэффициентом $k=2,08$ при критическом значении $k_{\text {кр }}=1,7$.

По всей видимости, уменьшение интенсивности пелитизации в газонасыщенных пластах (рис. 1) обусловлено эффектом консервации углеводородами геохимических процессов (закономерность Чепикова) [15]. В отличие от газонасыщенных интервалов, в нефтенасыщенных пластах данного участка интенсивность пелитизации повышается. Это связано с особенностями фазового разделения смеси нефти и воды (в отличие от газа) при её заполнении коллектора.

Исследования указывают на то, что при интенсивности пелитизации меньше граничной величины 0,084 усл. ед. вероятность выявления газонасыщенных пластов на Западно-Тамбейском участке равна $80 \%$.

По Северо-Тамбейскому участку выборка газонасыщенных интервалов составила 74 значения (по четырем параметрам) и 43 значения для водонасыщенных пластов. Проведенный статистический анализ результатов интерпретаций определил параметриндикатор газонасыщенности пластов. Это интенсивность вторичной карбонатизации, средняя величина которой в УВ насыщенной породе на $63 \%$ больше данной средней величины водонасыщенных пластов (рис. 2). Остальные параметры меняются незначительно.

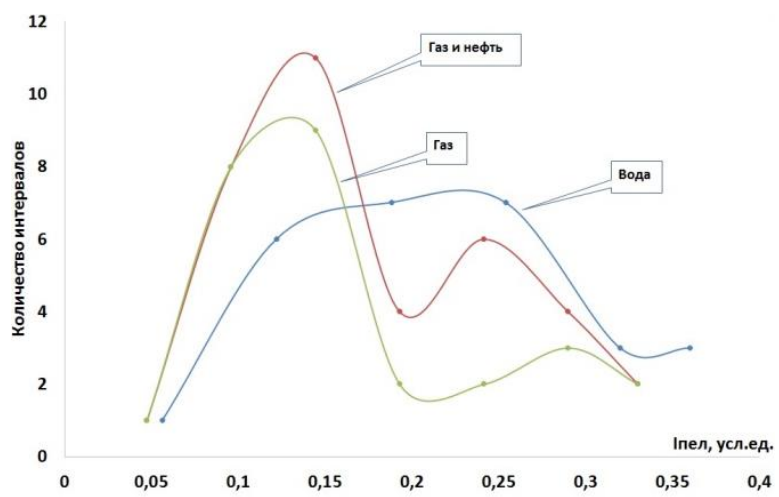

Рис. 1. Гистограммы плотности распределения параметра интенсивности пелитизации в водо- $и$ нефтегазонасыщенных песчаных интервалах 3 падно-Тамбейского участка

Fig. 1. Histograms of distribution density of the pelitization intensity parameter in water and hydrocarbon saturated sand intervals of the West Tambey area

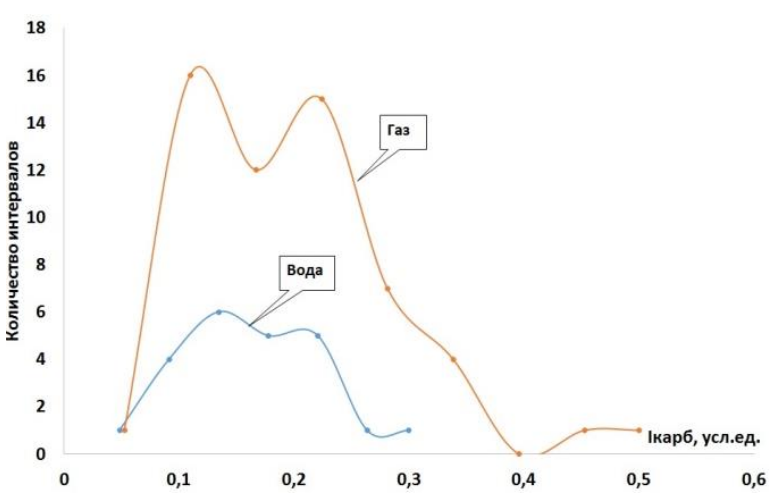

Рис. 2. Гистограммы плотности распределения параметра интенсивности вторичной карбонатизации в водо- и газонасыщенных песчаных интервалах Северо-Тамбейского участка

Fig. 2. Histograms of distribution density of the secondary carbonatization intensity parameter in the water and hydrocarbonate saturated sand intervals of the North Tambey area

Если из выборки убрать нулевые значения, средняя величина интенсивности карбонатизации газонасыщенного коллектора будет больше на $23 \%$ от средней интенсивности в водоносном пласте. Кроме того, парный двухвыборочный $t$-тест для средних показал отличие выборок интенсивностей карбонатизации газонасыщенных и водонасыщенных пластов с коэффициентом $k=1,9$ при критическом значении $k_{\text {кр }}=1,7$.

При интенсивности вторичной карбонатизации больше граничной величины 0,22 усл. ед. вероятность выявления газонасыщенных пластов на СевероТамбейском участке равна $80 \%$.

Значимое отличие величин средней интенсивности вторичной карбонатизации при выборках с нулевыми и в отсутствие нулевых значений объясняется тем, что в газоносных пластах Северо-Тамбейского участка карбонатизация встречается в 2 раза чаще, чем в водоносных горизонтах.

Отличие геохимических процессов в песчаных пластах Северо-Тамбейского участка от Западно- 
Тамбейского может быть обусловлено только различием в скорости заполнения флюидом коллектора. При малой скорости заполнения емкости газом химически агрессивная вода, поступающая с глубинных горизонтов, успевает преобразовать породу до её консервации. Что и происходит на северном участке месторождения.

Поровые воды на стадии катагенеза имеют щелочной характер, и минеральные компоненты породы находятся в геохимическом равновесии с ними. Приход в коллектор миграционных кислых вод, сопровождающих нефть, приводит к нарушению этого равновесия в сторону увеличения кислотности среды, в результате чего начинается изменение минеральной матрицы породы и её растворение. В условиях затрудненного водообмена по мере увеличения концен- трации в растворах катионов щелочноземельных элементов в результате каолинитизации и пелитизации полевых шпатов кислотные свойства растворов ощелачиваются и растворение сменяется вторичным минералообразованием. В нейтральных и слабощелочных условиях $(\mathrm{pH}=7,0-7,5)$ реализуется серицитизация плагиоклазов, начинается сидеритизация биотита. Растворяющийся биотит, взаимодействуя с водой, приводит к локальному повышению щёлочности порового раствора и интенсивной вторичной карбонатизации. С ростом щелочности по мере удаления от ВНК образуются изоморфнозамещенные кальциты: в верхних частях более железистые и магнезиальные, в нижних более кальциевые (нейтральные, слабощелочные и щелочные среды) [16-20].

Таблица. Результаты статистической интерпретации данных ГИС и исследований образцов керна СевероТамбейского участка

Table. $\quad$ Results of statistical interpretation of well log data and core samples from the North Tambey area

\begin{tabular}{|c|c|c|c|c|c|c|c|c|c|}
\hline \multirow{3}{*}{ № } & \multirow{3}{*}{ 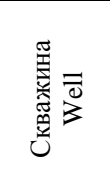 } & \multirow{3}{*}{$\begin{array}{c}\text { Интервал } \\
\text { исслед., м } \\
\text { Research } \\
\text { interval, m }\end{array}$} & \multirow{3}{*}{ 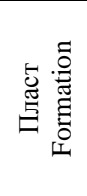 } & \multicolumn{4}{|c|}{$\begin{array}{c}\text { Стат. } \\
\text { интенсивность } \\
\text { Statistical intensity }\end{array}$} & \multicolumn{2}{|c|}{$\begin{array}{l}\text { Исследование керна } \\
\text { Core study }\end{array}$} \\
\hline & & & & $i_{\text {каол }}$ & $i_{\text {карб }}$ & $\mathrm{i}_{\text {пир }}$ & $\mathrm{i}_{\text {пел }}$ & \multirow{2}{*}{$\begin{array}{l}\text { Аутигенный цемент } \\
\text { Authigenic cement }\end{array}$} & \multirow{2}{*}{$\begin{array}{l}\text { Постседиментация } \\
\text { Post-sedimentation }\end{array}$} \\
\hline & & & & conve & $\begin{array}{l}\text { усл. } \\
\text { ventiol }\end{array}$ & $\begin{array}{l}\text {. ед. } \\
\text { nally }\end{array}$ & units & & \\
\hline 1 & C-T-205 & $2693,6-2703,2$ & БЯ8 & \begin{tabular}{|l|l|}
0,07 \\
\end{tabular} & 0,22 & 0,18 & 0,06 & $\begin{array}{l}\text { Единичные пленки и примаз- } \\
\text { ки лейкоксена } 0,4 \% \text {; пелито- } \\
\text { морфный сидерит 0,9 \%; } \\
\text { кальцит отдельные знаки; } \\
\text { аутигенный кварц 0,2 \% } \\
\text { Single films and smears of } \\
\text { leucoxene } 0,4 \% \text {; pelitomorphic } \\
\text { siderite } 0,9 \% \text {; calcite isolated } \\
\text { marks; authigenic quartz 0,2 \% }\end{array}$ & $\begin{array}{l}\text { Пелитизация, серицитизация, редко ча- } \\
\text { стичное растворение полевого шпата; } \\
\text { гидратизация, пластическая деформация } \\
\text { слюды; хлоритизация, сидеритизация } \\
\text { биотита; слабо проявленная регенерация } \\
\text { единичных зерен кварца } \\
\text { Pelitization, sericitization, rarely partial } \\
\text { dissolution of feldspar; hydration, plastic } \\
\text { deformation of mica; chloritization, } \\
\text { sideritization of biotite; weakly manifested } \\
\text { regeneration of single quartz grains }\end{array}$ \\
\hline 2 & C-T-205 & $2720,0-2727,4$ & БЯ10 & 0,00 & 0,00 & 0,00 & 0,21 & $\begin{array}{l}\text { Лейкоксен } 1,1 \% \text {; пирит } \\
0,1 \text { \%; аутигенный кварц } \\
0,1 \% \text {; кальцит 0,7 \% } \\
\text { Leucoxene } 1,1 \% \text {; pyrite } 0,1 \% \text {; } \\
\text { authigenic quartz } 0,1 \% \text {; calcite } \\
0,7 \% \text {. } \\
\\
\end{array}$ & $\begin{array}{l}\text { Пелитизация, серицитизация, иногда ча- } \\
\text { стичное растворение полевого шпата; гид- } \\
\text { ратизация, пластическая деформация слю- } \\
\text { ды; хлоритизация биотита; растворение и } \\
\text { слабая регенерация отдельных зерен кварца } \\
\text { Pelitization, sericitization, sometimes } \\
\text { partial dissolution of feldspar; hydration, } \\
\text { plastic deformation of mica; chloritization } \\
\text { of biotite; dissolution and weak } \\
\text { regeneration of individual quartz grains }\end{array}$ \\
\hline 3 & C-T-205 & $2802,2-2811,8$ & БЯ12 & 0,00 & 0,36 & 0,14 & 0,23 & $\begin{array}{l}\text { Лейкоксен (прерывистые } \\
\text { пленки и отдельные примаз- } \\
\text { ки) } 1,2 \% \text {; пирит } 0,1 \% \text {; каль- } \\
\text { цит 2,8 \% } \\
\text { Leucoxene (discontinuous films } \\
\text { and separate smears) } 1,2 \% \text {; } \\
\text { pyrite } 0,1 \% \text {; calcite } 2,8 \% \text {. }\end{array}$ & $\begin{array}{l}\text { Пелитизация, серицитизация, деформа- } \\
\text { ция (единичные зерна) полевого шпата; } \\
\text { гидратизация, пластическая деформация } \\
\text { слюды; хлоритизация биотита; раство- } \\
\text { рение кварца; частичная карбонатизация } \\
\text { обломочного материала } \\
\text { Pelitization, sericitization, deformation } \\
\text { (single grains) of feldspar; hydration, } \\
\text { plastic deformation of mica; chloritization } \\
\text { of biotite; dissolution of quartz; partial } \\
\text { carbonatization of clastic material }\end{array}$ \\
\hline 4 & C-T-203 & $2348,0-2357,6$ & ТП14 & 0,11 & 0,36 & 0,12 & 0,05 & $\begin{array}{l}\text { В разной степени раскристал- } \\
\text { лизованный каолинит (рас- } \\
\text { пределён пятнами, некоторые } \\
\text { поры с серицитом) 7,5 \%; } \\
\text { хлорит (пленки) 0,5\%; сиде- } \\
\text { рит (отдельные поры) } 0,9 \% \text {; } \\
\text { кальцит (распределен равно- } \\
\text { мерно) } 14,7 \% \\
\text { Crystallized kaolinite to varying } \\
\text { degrees (distributed by spots, } \\
\text { some pores with sericite) 7,5\%; } \\
\text { chlorite (films) } 0,5 \% \text {; siderite } \\
\text { (separate pores) } 0,9 \% \text { calcite } \\
\text { (evenly distributed) } 14,7 \%\end{array}$ & $\begin{array}{l}\text { Пелитизация, серицитизация, каолини- } \\
\text { зация и растворение полевого шпата; } \\
\text { гидратация, пластическая деформация } \\
\text { слюд, хлоритизация и сидеритизация } \\
\text { биотита; растворение и регенерация } \\
\text { кварца. Карбонатизация обломочного } \\
\text { материала } \\
\text { Pelitization, sericitization, kaolinization } \\
\text { and feldspar dissolution; hydration, plastic } \\
\text { deformation of micas, chloritization and } \\
\text { sideritization of biotite; dissolution and } \\
\text { regeneration of quartz. Detrital material } \\
\text { carbonation }\end{array}$ \\
\hline
\end{tabular}




\begin{tabular}{|c|c|c|c|c|c|c|c|c|c|}
\hline 5 & C-T-203 & $2356,6-2375,2$ & ТП14(1) & 0,05 & 0,20 & 0,22 & 0,11 & $\begin{array}{l}\text { В разной степени раскристал- } \\
\text { лизованный каолинит (рас- } \\
\text { пределен неравномерно) } \\
8,4 \text { \%; хлорит (пленки) 1,0 \%; } \\
\text { сидерит (отдельные поры) } \\
1,9 \% \\
\text { Crystallized kaolinite to varying } \\
\text { degrees (unevenly distributed) } \\
\text { 8,4 \%; chlorite (films) 1,0 \%; } \\
\text { siderite (separate pores) } 1,9 \%\end{array}$ & $\begin{array}{l}\text { Пелитизация, серицитизация и раство- } \\
\text { рение полевого шпата; гидратация, пла- } \\
\text { стическая деформация слюд, хлоритиза- } \\
\text { ция и сидеритизация биотита; растворе- } \\
\text { ние и регенерация кварца } \\
\text { Pelitization, sericitization and dissolution } \\
\text { of feldspar; hydration, plastic deformation } \\
\text { of micas, chloritization and sideritization of } \\
\text { biotite; dissolution and regeneration of } \\
\text { quartz }\end{array}$ \\
\hline 6 & C-T-203 & $2516,8-2526,4$ & ТП18 & 0,11 & 0,41 & 0,16 & 0,00 & $\begin{array}{l}\text { Плохо раскристаллизованный } \\
\text { каолинит (распределен не- } \\
\text { равномерно) 6,4 \%; хлорит } \\
\text { (пленки и единичные поры) } \\
1,8 \text { \%; гидрослюда (поры и } \\
\text { пленки) 0,5 \%; сидерит (от- } \\
\text { дельные поры) 0,9 \%; кальцит } \\
6,1 \% \\
\text { Poorly crystallized kaolinite } \\
\text { (unevenly distributed) 6,4 \%; } \\
\text { chlorite (films and single pores) } \\
1,8 \% \text {; hydromica (pores and } \\
\text { films) 0,5\%; siderite (separate } \\
\text { pores) } 0,9 \% \text {; calcite 6,1 \% }\end{array}$ & $\begin{array}{l}\text { Пелитизация, серицитизация и раство- } \\
\text { рение полевого шпата; гидратация, пла- } \\
\text { стическая деформация слюд, хлоритиза- } \\
\text { ция и сидеритизация биотита; растворе- } \\
\text { ние и регенерация кварца. Частичная } \\
\text { карбонатизация обломочного материала } \\
\text { Pelitization, sericitization and dissolution } \\
\text { of feldspar; hydration, plastic deformation } \\
\text { of micas, chloritization and sideritization of } \\
\text { biotite; dissolution and regeneration of } \\
\text { quartz. Partial carbonation of clastic } \\
\text { material }\end{array}$ \\
\hline 7 & C-T-201 & $2631,2-2641,8$ & XM2 & 0,00 & 0,32 & 0,22 & 0,07 & $\begin{array}{l}\text { Пелитоморфный сидерит } \\
10,1 \text { \%, приуроченный в ос- } \\
\text { новном к слойкам разнозер- } \\
\text { нистого алевролита; пирит в } \\
\text { основном по углистой расти- } \\
\text { тельной органике } \\
\text { Pelitomorphic siderite } 10,1 \%, \\
\text { confined mainly to layers of } \\
\text { different-grained siltstone; } \\
\text { pyrite is mainly based on } \\
\text { carbonaceous plant organic } \\
\text { matter }\end{array}$ & $\begin{array}{l}\text { Пелитизация, серицитизация, иногда } \\
\text { растворение полевого шпата; пластиче- } \\
\text { ская деформация, гидратация, расщеп- } \\
\text { ление слюды; хлоритизация, сидерити- } \\
\text { зация биотита; растворение единичных } \\
\text { зерен кварца } \\
\text { Pelitization, sericitization, sometimes } \\
\text { dissolution of feldspar; plastic deformation, } \\
\text { hydration, cleavage of mica; chloritization, } \\
\text { sideritization of biotite; dissolution of } \\
\text { single grains of quartz }\end{array}$ \\
\hline 8 & C-T-201 & $1800,8-1810,4$ & ТП1 & 0,05 & 0,08 & 0,00 & 0,21 & $\begin{array}{l}\text { Редкие примазки и пленки } \\
\text { лейкоксена 1-2 \%; пирит до- } \\
\text { ли процента } \\
\text { Rare smears and leucoxene } \\
\text { films 1-2\%; pyrite of a fraction } \\
\text { of a percent }\end{array}$ & $\begin{array}{l}\text { Пелитизация, серицитизация, растворе- } \\
\text { ние полевого шпата; гидратизация слю- } \\
\text { ды; растворение кварца } \\
\text { Pelitization, sericitization, feldspar } \\
\text { dissolution; hydration of mica; dissolution } \\
\text { of quartz }\end{array}$ \\
\hline 9 & C-T-201 & $2511,4-2521,0$ & ТП18 & 0,24 & 0,47 & 0,22 & 0,18 & $\begin{array}{l}\text { Лейкоксен (единичные пре- } \\
\text { рывистые пленки, и отдель- } \\
\text { ные примазки) 1-2 \%; пирит } \\
\text { доли процента; сидерит в } \\
\text { среднем составляет 7-8 \%; } \\
\text { кальцит 5-6\% } \\
\text { Leucoxene (single intermittent } \\
\text { films, and separate smears) } \\
1-2 \% \text {; pyrite of a fraction of a } \\
\text { percent; siderite averages } \\
7-8 \% \text {; calcite 5-6\% }\end{array}$ & $\begin{array}{l}\text { Частичное растворение, пелитизация, } \\
\text { серицитизация полевого шпата; раство- } \\
\text { рение зерен кварца; пластическая де- } \\
\text { формация, гидратация слюды; хлорити- } \\
\text { зация, сидеритизация биотита; слабая } \\
\text { карбонатизация обломочного материала } \\
\text { Partial dissolution, pelitization, } \\
\text { sericitization of feldspar; dissolution of } \\
\text { quartz grains; plastic deformation, } \\
\text { hydration of mica; chloritization, } \\
\text { sideritization of biotite; weak } \\
\text { carbonatization of clastic material }\end{array}$ \\
\hline 10 & C-T-201 & $2628,6-2638,2$ & ТП22 & 0,14 & 0,45 & 0,22 & 0,14 & $\begin{array}{l}\text { Пирит по единичным угли- } \\
\text { стым растительным остаткам } \\
\text { доли процента; единичные } \\
\text { примазки лейкоксена; пели- } \\
\text { томорфный сидерит по био- } \\
\text { титу и в виде пятнистых вы- } \\
\text { делений (10,4 \%), приурочен } \\
\text { в основном к слойкам угли- } \\
\text { сто-слюдистого состава; } \\
\text { кальцит 25-26 \% } \\
\text { Pyrite on single carbonaceous } \\
\text { plant residues of a fraction of a } \\
\text { рercent; single leucoxene } \\
\text { smears; pelitomorphic siderite } \\
\text { after biotite and in the form of } \\
\text { spotty excretions (10,4 \%), } \\
\text { confined mainly to layers of } \\
\text { carbonaceous-micaceous } \\
\text { composition; calcite } 25-26 \%\end{array}$ & $\begin{array}{l}\text { Пелитизация, серицитизация, иногда ча- } \\
\text { стичная каолинизация полевого шпата; } \\
\text { гидратизация, пластическая деформа- } \\
\text { ция, редко расщепление слюды; сидери- } \\
\text { тизация, иногда хлоритизация биотита; } \\
\text { частичная карбонатизация обломочного } \\
\text { материала } \\
\text { Pelitization, sericitization, sometimes partia } \\
\text { lkaolinization of feldspar; hydration, plastic } \\
\text { deformation, rarely mica splitting; } \\
\text { sideritization, sometimes chloritization of } \\
\text { biotite; partial carbonatization of clastic } \\
\text { material }\end{array}$ \\
\hline
\end{tabular}


В таблице показаны результаты статистическокорреляционной интерпретации материалов ГИС в десяти песчаных интервалах трех скважин СевероТамбейского участка, а именно интенсивности вторичных процессов каолинитизации, карбонатизации, пиритизации и пелитизации. В последних двух столбцах даны результаты петрологических исследований шлифов керна на предмет определения содержания аутигенного цемента и постседиментационных геохимических процессов. При сопоставлении интенсивностей вторичных процессов с описанием результатов петрологических исследований мы видим, что интенсивность вторичной карбонатизации неплохо коррелирует с результатами исследований шлифов. Например, при значительных показаниях интенсивности $i_{\text {карб}}=0,36-0,47$ усл. ед. (строки $\left.3,4,6,7,9,10\right)$ в описании шлифов процессы сидеритизации и кальцитизации проявляются с достаточно большим содержанием данных вторичных карбонатов ( 6-35 \%). И наоборот, при интенсивности карбонатизации равной нулю (строки 2, 8) в описании результатов исследования шлифов их содержание отсутствует либо весьма незначительно (меньше $1 \%$ ).

Если сопоставить величины интенсивностей пиритизации с описанием шлифов, то мы видим их полное несоответствие. Это связано с тем, что в данном случае вместо пиритизации проходит процесс хлоритизации с последующей сидеритизацией биотитов. Хлоритизация идет в кислой среде $(\mathrm{pH}=5,0-6,0)$ после каолинитизации, при её устойчивости в щелочной. Как известно, все минералы, образующиеся в результате перечисленных процессов, содержат железо. В результате гидратации с сидеритезацией железосодержащих биотитов и образованием электропроводящих крустифицированных пленок глинистых минералов может образоваться электропроводящая цепь, связанная с содержанием железа и понижающая УЭС породы, интерпретируемая как пиритизация. Это заметно по результатам анализа таблицы - там, где отсутствует в описании шлифов «гидратация, пластическая деформация слюд, хлоритизация и сидеритизация биотита» интенсивность «пиритизации» равна нулю (строки 2 и 8 ).

В интервалах (таблица, строки 4, 6, 9, 10), где статистическая интенсивность вторичной каолинитизации проявилась в пределе $i_{\text {каол }>}>0,1$ усл. ед., в описаниях шлифов обнаруживаются следующие формулировки: «Плохо раскристаллизованный каолинит; каолинизация и растворение полевого шпата; частичное растворение». Очевидно, что в исследуемых интервалах после поступления внешних кислых флюидов ощелачивание раствора проходило через определенное время, достаточное для образования вторичных каолинитов. Далее процесс интенсивной карбонатизации контролировался процессом ощелачивания среды.

Лабораторные определения содержаний общих карбонатов в образцах песчаных пород, в интервалах проведения статистической интерпретации данных ГИС исследуемых скважин, позволили сопоставить величины интенсивностей вторичной карбонатизации с усреднёнными (по изучаемому интервалу) содержаниями общих карбонатов. Сопоставление выборочных данных выявило их хорошее соответствие с коэффициентом корреляции линейного тренда 0,73 (рис. 3).

Статистически значимый разброс отдельных выборочных значений относительно линии тренда объясняется следующими неувязками: во-первых, по керну были определены средние содержания общих карбонатов, а по данным ГИС - интенсивности процессов вторичной карбонатизации; во-вторых, точность определения усредненных величин содержаний по интервалу зависит от количества изученных образцов в данном интервале, однако в некоторых случаях эмпирической статистики явно не хватало.

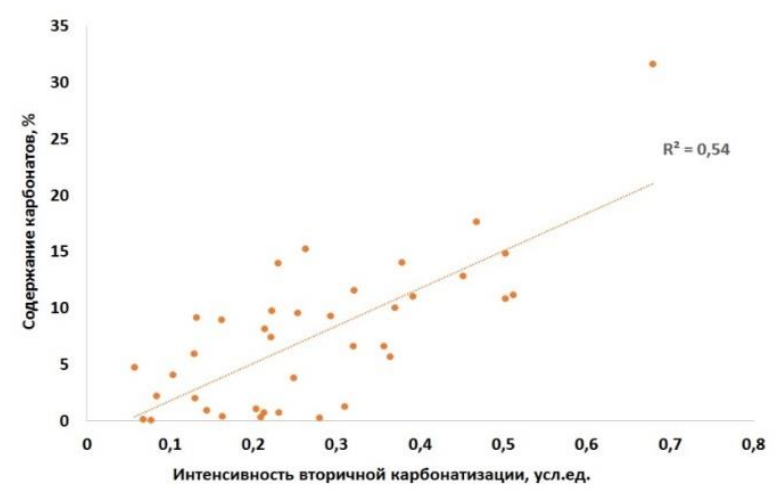

Pис. 3. Сопоставление средних содержаний общих карбонатов, определенных по образиам керна, с интенсивностью вторичных карбонатов, вычисленных по данным ГИС в песчаных интервалах Тамбейского месторождения

Fig. 3. Comparison of the average contents of total carbonates determined from core samples with the intensity of secondary carbonates calculated from well log data in the sandy intervals of the Tambey field

\section{Заключение}

Итак, на основании результатов проведенных исследований применения технологии статистическокорреляционной интерпретации материалов ГИС в песчаных коллекторах Тамбейского месторождения для выявления пропущенных УВ насыщенных низкоомных коллекторов можно сделать следующие выводы:

1. Вычисленные статистические интенсивности вторичных процессов (каолинитизации, карбонатизации, пиритизации и пелитизации) в песчаных интервалах полностью соответствуют результатам лабораторных исследований керна.

2. Если при выявлении в песчаных коллекторах Западно-Тамбейского участка интенсивность вторичной пелитизации оказалась менее 0,084 усл. ед., то с вероятностью $20 \%$ исследуемый интервал можно считать УВ насыщенным.

3. На Северо-Тамбейском участке с $80 \%$ вероятностью индикатором газонасыщенности пласта является интенсивность вторичной карбонатизации при условии превышения её критической величины 0,22 усл. ед. 
Таким образом, интенсивности определенных вторичных геохимических процессов играют роль в качестве атрибутов нефтегазонасыщенности в низкоомных песчаных интервалах Тамбейского месторождения. Вычисление интенсивностей осуществляется с

\section{СПИСОК ЛИТЕРАТУРЫ}

1. Лебедев Б.А. Геохимия эпигенетических процессов в осадочных бассейнах. - Л.: Изд-во «Недра», 1992. - 239 с.

2. Authigenic kaolin and illitic minerals during burial diagenesis of sandstones: a review / B. Lanson, D. Beaufort, G. Berger, A. Bauer, A. Cassagnabere, A. Meunier // Clay minerals. - 2002. V. 37. - Iss. 1. - P. 1-22.

3. Chlorite in sandstones / R.H. Worden, J. Griffiths, L.J. Wooldridge, J.E.P. Utley, A.Y. Lawan, D.D. Muhammed, N. Simon, P.J. Armitage // Earth-Science Reviews. - 2020. - V. 204 . P.103-105.

4. Origins of authigenic minerals and their impacts on reservoir quality of tight sandstones: Upper Triassic Chang-7 Member, Yanchang Formation, Ordos Basin, China / Y.L. Zhang, Z.D. Bao, Y. Zhao, L. Jiang, Y.Q. Zhou, F.H. Gong // Australian Journal of Earth Sciences. - 2017. - V. 64. - Iss. 4. - P. 519-536.

5. Milliken K.L. Late diagenesis and mass transfer in sandstoneshale sequences // Treatise on Geochemistry. - 2003. - V. 7. P. $159-190$

6. Мельник И.А. Определение интенсивности геохимических процессов по материалам геофизических исследований скважин. - Новосибирск: Изд-во СНИИГГиМС, 2016. - 146 с.

7. Мельник И.А. Интенсивности процессов наложенного эпигенеза как индикаторы нефтенасыщенности песчаных коллекторов // Известия Томского политехнического университета. Инжиниринг георесурсов. - 2019. - Т. 330. - № 6. - С. 90-97.

8. Мельник И.А., Шарф И.В., Иванова М.П. Статистический параметр двойного электрического слоя как индикатор нефтенасыщенности нижнесреднеюрских отложений Томской области // Нефтяное хозяйство. - 2018. - № 10. - С. 24-26.

9. Мельник И.А. Причины образования нефтенасыщенных низкоомных коллекторов // Геология нефти и газа. - 2018. № 6. - C. 129-136.

10. Mechanisms of smart waterflooding in carbonate oil reservoirs / J. Hao, S. Mohammadkhani, H. Shahverdi, M.N. Esfahany, A. Shapiro // Journal of Petroleum Science and Engineering. 2019. - V. 179. - P. 276-291.

11. Nasralla R.A., Nasr H.A. Double-layer expansion: is it a primary mechanism of improved oil recovery by low-salinity waterflooding // Journal of Petroleum Science and Engineering. 2014. - V. 17. - P. 1-11. помощью инновационной технологии статистическокорреляционной интерпретации материалов ГИС. В качестве геофизических материалов можно использовать как старые, так и новые данные фондов в формате Las.

12. Природный тектонический насос углеводородов и вторичная доломитизация - порождение тектоно-гидротермальной активности рифтогенного осадочного бассейна / А.Д. Коробов, Л.А. Коробова, Е.Ф. Ахлестина, А.Т. Колотухин, В.М. Мухин // Известия Саратовского университета. Серия «Науки о Земле». -2015 . - Т. 15. - № 3. - С. 46-52.

13. Карнюшина Е.Е. Основные причины возникновения зон карбонатной цементации в толщах нефтегазоносных бассейнов // Вестник Московского университета. Раздел геология. -2012 . № 5. - C. 47-49.

14. Pyrite formation from $\mathrm{FeS}$ and $\mathrm{H} 2 \mathrm{~S}$ is mediated through microbial redox activity / J. Thiel, J.M. Byrne, A. Kappler, B. Schink, M. Pester // Proceedings of the National Academy of Sciences. 2019. - V. 116. - P. 6897-6902.

15. Зарипов О.Г., Сонич В.П. Влияние литологии пород - коллекторов на удельное электрическое сопротивление пластов // Нефтяное хозяйство. - 2001. - № 9. - С. 18-21.

16. Чепиков К.Р., Ермолова Е.П., Орлова Н.А. Эпигенетические минералы как показатели времени прихода нефти в песчаные промышленные коллекторы // Докл. АН СССР. - 1959. № 5. - С. 1097-1099.

17. Роль дизъюнктивной тектоники в формировании пустотного пространства в коллекторах пласта Ю13 ЗападноМоисеевского участка Двуреченского нефтяного месторождения (Томская область) / Н.М. Недоливко, А.В. Ежова, Т.Г. Перевертайло, Е.Д. Полумогина // Известия Томского политехнического университета. - 2005. - Т. 308. - № 5.- С. 47-53.

18. Предтеченская Е.А., Шиганова О.В., Фомичев А.С. Катагенетические и гидрохимические аномалии в нижнесреднеюрских нефтегазоносных отложениях Западной Сибири как индикаторы флюидодинамических процессов в зонах дизьюнктивных нарушений // Литосфера. - 2009. - № 6. - С. 54-65.

19. Velbel M.A. Influence of surface area, surface characteristics, and solution composition on feldspar weathering rates // Symposium Series: Geochemical Processes at Mineral Surfaces. - 1986. № 323. - P. 614-634.

20. Bjorkum P.A., Gielsvik N. An isochemical model for formation of authigenic kaolinite, feldspar and illite in sediments // Journal of Sedimentary Petrology. - 1988. - V. 58. - P. 506-511.

Поступила 12.04.2021 2.

\section{Информация об авторах}

Мельник И.А., доктор геолого-минералогических наук, профессор отделения нефтегазового дела Национального исследовательского Томского политехнического университета.

Родивилов Д.Б., заместитель начальника отдела анализа и интерпретации данных ГИС, филиал Газпром недра НТЦ ООО «Газпром недра».

Никитин И.А., начальник группы отдела по проектированию и анализу эффективности геолого-техн ических мероприятий НИПИ «СургутНИПИнефть». 


\title{
SECONDARY GEOCHEMICAL PROCESSES AS HYDROCARBON SATURATION ATTRIBUTE OF THE SAND RESERVOIRS OF TAMBEY FIELD
}

\author{
Igor A. Melnik ${ }^{1}$ \\ melnik@tpu.ru
}

\author{
Danila B. Rodivilov 1 , \\ rodivilovdb@gmail.com \\ Ivan A. Nikitin ${ }^{3}$ \\ nikitin_ivan_alex@mail.ru \\ 1 National Research Tomsk Polytechnic University, \\ 30, Lenin avenue, Tomsk, 634050, Russia. \\ 2 Branch of Gazprom nedra, \\ 70, Gertsena sreet, Tyumen, 625000, Russia. \\ 3 «SurgutNIPIneft», \\ 48, Entuziastov street, Surgut, 628415, Russia.
}

The relevance of the study is determined by the considered possibility, in the absence of a core, to identify missed productive deposits in sandy intervals using materials from both the old and the new well logging fund. Modern requirements for the creation and development of the mineral resource base of the Russian Federation at the highest level presuppose the introduction of a large number of fundamentally new deposits and deposits, the profitability of which is established by the level of knowledge. In many cases, it is simply necessary to reduce the time frame and capital costs for exploration work due to the application and additional exploration of data from the past studied fields. The area of the Tambey field is quite promising in light of the active development of the Yamal oil and gas fields.

The aim of the research is the illustration of the use of such parameters as statistical intensities of secondary pelitization and carbonatization as indicators of oil and gas saturation of sandy reservoirs in various areas of the Tambey field.

Objects: cretaceous sandy deposits of the oil and gas field of the Tambey area of the Yamal Peninsula.

Results. The paper demonsitrates the petrological and geochemical indicators of oil and gas content and their determination based on logging data. Comparison of the results of statistical interpretation of logging data with the results of petrographic core study is illustrated. The work uses an innovative technology of statistical interpretation of logging materials for identifying the intensities of secondary geochemical processes in indication of oil and gas reservoirs. It was confirmed that in the North-Tambey area, with $80 \%$ probability, the indicator of the formation gas saturation is the intensity of secondary carbonatization, provided that its critical value is exceeded by 0,22 conventional units, and in the West-Tambey area, the indicator of the oil and gas saturation of reservoirs is the intensity of secondary pelitization, provided that their values are exceeded up to 0,084 conventional units.

\section{Key words:}

Superimposed-epigenetic process, secondary pelitization, secondary carbonation, low-impedance reservoir hydrocarbons, geochemical indicator of hydrocarbon saturation, well logging.

\section{REFERENCES}

1. Lebedev B.A. Geokhimiya epigeneticheskikh protsessov $v$ osadochnykh basseynakh [Geochemistry of epigenetic processes in sedimentary basins]. Leningrad, Nedra Publ., 1992. 239 p.

2. Lanson B., Beaufort D., Berger G., Bauer A., Cassagnabere A., Meunier A. Authigenic kaolin and illitic minerals during burial diagenesis of sandstones: a review. Clay minerals, 2002, vol. 37, no. 1 , pp. 1-22.

3. Worden R.H., Griffiths J., Wooldridge L.J., Utley J.E.P., Lawan A.Y., Muhammed D.D., Simon N., Armitage P.J. Chlorite in sandstones. Earth-Science Reviews, 2020, vol. 204, pp. 103-105.

4. Zhang Y.L., Bao Z.D., Zhao Y., Jiang L., Zhou Y.Q., Gong F.H Origins of authigenic minerals and their impacts on reservoir quality of tight sandstones: Upper Triassic Chang-7 Member, Yanchang Formation, Ordos Basin, China. Australian Journal of Earth Sciences, 2017, vol. 64, no. 4, pp. 519-536.

5. Milliken K.L. Late diagenesis and mass transfer in sandstone-shale sequences. Treatise on Geochemistry, 2003, vol. 7, pp. 159-190.

6. Melnik I.A. Opredelenie intensivnosti geokhimicheskikh protsessov po materialam geofizicheskikh issledovaniy skvazhin [Determination of the intensity of geochemical processes based on well logging data]. Novosibirsk, SNIIGGiMS Publ., 2016. 146 p.

7. Melnik I.A. Intensity of superimposed epigenesis processes as indicators of oil saturation in sandy reservoirs. Bulletin of the
Tomsk Polytechnic University. Geo Assets Engineering, 2019, vol. 330, no. 6, pp. 90-97. In Rus.

8. Melnik I.A., Sharf I.V., Ivanova M.P. Statistical parameter of the double electric layer as an indicator of oil saturation of the lowerMiddle Jurassic deposits of the Tomsk region. Oil industry, 2018, no. 10, pp. 24-26. In Rus.

9. Melnik I.A. The reasons for the formation of oil-saturated lowresistance reservoirs. Geology of oil and gas, 2018, no. 6, pp. 129-136. In Rus.

10. Hao J., Mohammadkhani S., Shahverdi H., Esfahany M.N., Shapiro A. Mechanisms of smart waterflooding in carbonate oil reservoirs. Journal of Petroleum Science and Engineering, 2019, vol. 179, pp. 276-291

11. Nasralla R.A., Nasr H.A. Double-layer expansion: is it a primary mechanism of improved oil recovery by low-salinity waterflooding. Journal of Petroleum Science and Engineering, 2014, vol. 17, pp. 1-11.

12. Korobov A.D., Korobova L.A., Akhlestina E.F., Kolotukhin A.T., Mukhin V.M. Natural tectonic pump of hydrocarbons and secondary dolomitization - the generation of tectonichydrothermal activity of the riftogenic sedimentary basin. Saratov University Publ. Series «Earth Sciences», 2015, vol. 15, no. 3, pp. 46-52. In Rus.

13. Karnyushina E.E. The main reasons for the occurrence of zones of carbonate cementation in the strata of oil and gas basins. Moscow 
University Bulletin. Geology Section, 2012, no. 5, pp. 47-49. In Rus.

14. Thiel J., Byrne J.M., Kappler A., Schink B., Pester M. Pyrite formation from $\mathrm{FeS}$ and $\mathrm{H} 2 \mathrm{~S}$ is mediated through microbial redox activity. Proceedings of the National Academy of Sciences, 2019, vol. 116, pp. 6897-6902.

15. Zaripov O.G. Sonic V.P. Influence of lithology of rocks-reservoirs on the resistivity of reservoirs. Oil industry, 2001, no. 9, pp. 18-21. In Rus.

16. Chepikov K.R., Ermolova E.P., Orlova N.A. Epigeneticheskie mineral kak pokazateli vremeni prikhoda nefti $\mathrm{v}$ peschanye promyshlennye kollektory [Epigenetic minerals as indicators of the time of oil arrival in industrial sandy reservoirs]. Report Academy of Sciences of the USSR, 1959, no. 5, pp. 1097-1099.

17. Nedolivko N.M., Ezhova A.V., Perevertailo T.G., Polumogina E.D. The role of disjunctive tectonics in the formation of void space in the reservoirs of the Yu13 formation of the West Moiseevsky section of the Dvurechensk oil field (Tomsk region). Bulletin of the Tomsk Polytechnic University, 2005, vol. 308, no. 5, pp. 47-53.

18. Predtechenskaya E.A., Shiganova O.V., Fomichev A.S.

Catagenetic and hydrochemical anomalies in the Lower Middle Jurassic oil and gas deposits of Western Siberia as indicators of fluid-dynamic processes in zones of disjunctive disturbances. Lithosphere, 2009, no. 6, pp. 54-65. In Rus.

19. Velbel M.A. Influence of surface area, surface characteristics, and solution composition on feldspar weathering rates. Symposium Series: Geochemical Processes at Mineral Surfaces, 1986, no. 323, pp. 614-634.

20. Bjorkum P.A., Gielsvik N. An isochemical model for formation of authigenic kaolinite, feldspar and illite in sediments. Journal of Sedimentary Petrology, 1988, vol. 58, pp. 506-511.

Received: 12 April 2021.

\section{Information about the authors}

Igor A. Melnik, Dr. Sc., professor, National Research Tomsk Polytechnic University.

Danila B. Rodivilov, deputy head of the department of analysis and log data interpretation, Branch of Gazprom nedra. Ivan A. Nikitin, head of the group, «SurgutNIPIneft». 